\title{
Aplicações da Ferramenta de Prototipagem Arduino no ensino de Inteligência Artificial
}

\author{
Paola Cavalheiro Ponciano ${ }^{1}$, Mateus Henrique Dal Forno ${ }^{2}$ \\ ${ }^{1}$ Universidade Federal do Paraná (UFPR) - Setor Palotina \\ Palotina - PR. \\ ${ }^{2}$ Instituto Federal Farroupilha (IFFar) - Campus Frederico Westphalen \\ Frederico Westphalen - RS. \\ paolaponcianodufpr.br, mateus.dalfornodiffarroupilha.edu.br
}

\begin{abstract}
This paper presents the experience of use the Arduino platform applied of teaching artificial intelligence for students of the Information Systems course of IFFar - Campus São Borja. The experience permeated the use of the Fritzing simulation tool, as well as the interdisciplinary learning involving electronic, software engineering and programming topics. The results obtained with the experience pointed out a significant potential of the applied approach in the process of teaching and learning of the students with prototypes thought in the perspective of a greater interaction with the discipline, stimulation of the thinking and logical reasoning and written production of the results.
\end{abstract}

Resumo. Este escrito relata a experiência do uso da plataforma Arduino no ensino de inteligência artificial para estudantes de Sistemas de Informação do IFFar-Campus São Borja. A experiência permeou a utilização da ferramenta de simulação Fritzing, bem como o aprendizado interdisciplinar envolvendo temáticas de Eletrônica, Engenharia de Software e Programação. Os resultados obtidos com a experiência, apontaram um potencial significativo da abordagem aplicada no processo de ensino e aprendizado dos estudantes com protótipos pensados na perspectiva de uma maior interação com a disciplina, incentivo do pensamento e raciocínio lógico e produção escrita dos resultados.

\section{Introdução}

As novas metodologias alternativas de ensino, impulsionadas pelas Tecnologias de Informação e Comunicação (TICs), surgem como complementação curricular em sala de aula em todas as modalidades de ensino. Esse cenário nos direciona a um olhar mais crítico em relação às ditas metodologias tradicionais de ensino, visto que estas têm como pilar a compartimentalização de conteúdos, onde o professor é detentor total do saber e o estudante apenas reproduz o que lhe é transferido, com pouca ou quase nenhuma intervenção [Alarcão 2013, Libâneo 1992].

Contudo, a partir da criação da Lei de Diretrizes e Bases da Educação Brasileira [Brasil 1996], busca-se a construção de uma educação democrática centrada no protagonismo do estudante, que consequentemente implica uma transformação dos saberes e fazeres do profissional docente. Com base no exposto, este escrito traz em sua essência o relato da experiência de utilização da Plataforma de Prototipação Arduino Uno para o 
ensino prático de Agentes Inteligentes, na disciplina de Inteligência Artificial (IA), ofertada no primeiro semestre de 2018 aos estudantes do curso de Sistemas de Informação do IFFar - Campus São Borja.

O referido componente curricular busca abordar os conceitos fundamentais, métodos e estratégias que norteiam a produção e utilização de IA no mundo moderno. São abordados conteúdos relacionados à IA simbólica e não simbólica, métodos de representação de problemas e processamento de conhecimentos, estratégias de busca, redes neurais artificiais, lógica fuzzy, algoritmos genéticos e agentes inteligentes. Em conformidade com a ementa, o conteúdo de agentes inteligentes foi trabalhado de maneira prática, objetivando demonstrar como estes atuam nos ambientes através de seus sensores e atuadores. Para tal, utilizou-se o Arduino Uno, uma plataforma de prototipagem eletrônica de hardware livre, relativamente barata, que tem como pilar a facilidade e a flexibilidade em termos de hardware e software.

A experiência de que trata este escrito, teve como objetivos específicos: I. Proporcionar aos estudantes a experiência de elaboração de um projeto para implementação de agentes inteligentes; II. Utilizar a Engenharia de Software (ES) no desenvolvimento do projeto proposto; III. Possibilitar aos estudantes o conhecimento e compreensão do funcionamento dos componentes eletrônicos utilizando a ferramenta de simulação Fritzing ${ }^{1}$; IV. Desenvolvimento prático do projeto utilizando Arduino, e posterior socialização dos resultados por meio de seminários.

As demais seções deste artigo estão estruturadas conforme segue: A seção 2 apresenta a metodologia adotada. Na Seção 3 são descritos os resultados e discussões a respeito das experiências obtidas. Por fim, a Seção 4 apresenta as contribuições deste trabalho no âmbito acadêmico e institucional, seguido das referências consultadas.

\section{Métodos}

Inicialmente foi realizado o levantamento bibliográfico referente às temáticas que nortearam as práticas. Para tal, foram utilizados autores que estudam e pesquisam a IA como Russell e Norvig [2013] e Santos [2014]. Para realização do projeto foram utilizadas as referências relacionadas à ES, embasadas em autores como Pressman [2016], Sommerville [2011] e Guedes [2018]. Após esta etapa, foram listadas as ferramentas de simulação do Arduino e para demonstração dos componentes da placa.

$\mathrm{Na}$ etapa prática a turma, composta por 13 estudantes, foi dividida em grupos de trabalho, onde cada grupo recebeu um kit contendo uma placa arduino, protoboard, sensores, leds e demais componentes necessários para implementação prática do projeto. $\mathrm{Na}$ fase de desenvolvimento os estudantes tiveram a mediação docente para criação dos agentes, onde trabalharam de forma autônoma e utilizando conhecimentos obtidos nas disciplinas do curso. Os resultados dos trabalhos foram socializados em forma de seminário, onde cada grupo apresentou aos demais colegas da turma o produto desenvolvido. As contribuições da atividade são discutidas e apresentadas na Seção que segue.

\section{Resultados e Discussões}

Entender os conceitos relacionados foi fundamental para alcançar os objetivos propostos na atividade. Em conformidade com Russel e Norvig [2013, p.62], "Um agente é tudo

\footnotetext{
${ }^{1}$ Disponível em http://fritzing.org/home/.
} 
VII Congresso Brasileiro de Informática na Educação (CBIE 2018)

Anais dos Workshops do VII Congresso Brasileiro de Informática na Educação (WCBIE 2018)

o que pode ser considerado capaz de perceber seu ambiente por meio de sensores e de agir sobre esse ambiente por intermédio de atuadores". Assim, os princípios necessários para a construção do projeto precisaram ser abordados de forma teórica, utilizando aula expositiva e dialogada.

As primeiras abordagens práticas foram realizadas no simulador Fritzing, para apresentar as funcionalidades do Arduino, exercitar e identificar fenômenos tais como transferência digital e analógica de dados, carga elétrica e a organização lógica dos circuitos. Nesta atividade foram demonstrados os componentes principais para funcionamento, bem como a protoboard, que é uma matriz de contatos reutilizável que possibilita a fácil alteração do circuito eletrônico. Na protoboard são inseridos os jumpers, resistores, capacitores e sensores a serem empregados nos circuitos.

No ponto de vista da criação dos projetos os estudantes puderam identificar em seus grupos quais as possibilidades a serem criadas, levando em conta o material disponível nos kits. Os estudantes propuseram então a criação de protótipos utilizando sensores e atuadores conforme descrito na Tabela 1.

Tabela 1. Descrição dos projetos desenvolvidos

\begin{tabular}{|c|c|c|c|c|}
\hline GRUPO & PROJETO & AMBIENTE & ATUADOR & DESCRIÇÃO \\
\hline 01 & $\begin{array}{l}\text { Sensor de } \\
\text { Chuva }\end{array}$ & Externo & $\begin{array}{l}\text { Notificação por } \\
e \text {-mail (placa } \\
\text { de rede) }\end{array}$ & $\begin{array}{l}\text { Sistema para identificação de chuva e } \\
\text { notificação de seu início, utilizando } \\
\text { hardware aberto e notificações via } e \text { - } \\
\text { mail. }\end{array}$ \\
\hline 02 & $\begin{array}{l}\text { Sensor de } \\
\text { umidade } \\
\text { de solo }\end{array}$ & $\begin{array}{l}\text { Vaso de } \\
\text { Planta }\end{array}$ & $\begin{array}{l}\text { Led, Buzzer, } \\
\text { Notificação de } \\
e \text {-mail }\end{array}$ & $\begin{array}{l}\text { Sistema para identificação de baixa umi- } \\
\text { dade de solo no vaso de uma planta, com } \\
\text { notificação via led, buzzer e mensagem } \\
\text { no e-mail para que o usuário regue-a. }\end{array}$ \\
\hline 03 & $\begin{array}{l}\text { Sensor de } \\
\text { Nível de } \\
\text { Água }\end{array}$ & Recipiente & Led & $\begin{array}{l}\text { Sistema de notificação através de led, } \\
\text { acionado quando um determinado recipi- } \\
\text { ente possui certa quantidade definida de } \\
\text { líquido. }\end{array}$ \\
\hline
\end{tabular}

Com base na tabela acima, é possível observar que cada projeto envolveu um tipo de sensor, um tipo de agente e um tipo de ambiente. Todos os grupos utilizaram a IDE de desenvolvimento Arduino "Sketch", onde o código é implementado e carregado via conexão USB ao microcontrolador da placa. No projeto do Grupo 1 os testes do sensor de chuva foram realizados utilizando borrifador de água. Conforme a quantidade de borrifadas ele retorna ao programa uma notificação de que há contato com água.

No projeto do grupo 02, o sensor de umidade foi inserido no solo de uma planta que notifica através de led (vermelho $=$ solo seco, verde $=$ solo úmido), se a planta necessita de água. No caso de solo seco, o buzzer emite o som e através de placa de rede instalada, o usuário recebe uma notificação no $e$-mail de que a planta necessita ser regada. Por fim, no projeto do grupo 03, o sensor de nível de líquido aciona o led verde caso o recipiente tenha a quantidade estimada ou o led vermelho caso não alcance. A Figura 1 apresenta os projetos desenvolvidos pelos grupos em fase de teste.

\footnotetext{
${ }^{2}$ Disponível em https://www.arduino.cc/en/tutorial/sketch
} 


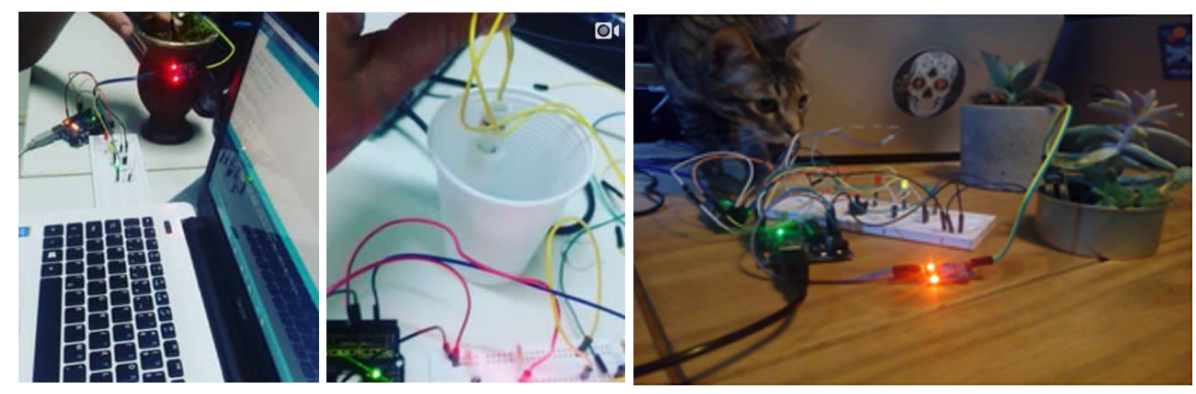

Figura 1. Projetos desenvolvidos pelos estudantes

Os exemplos citados foram criados pelos estudantes através de entrega prévia de um projeto de desenvolvimento observando requisitos elencados pelo grupo. Esta etapa, que possui como ênfase a engenharia de requisitos compreende o processo pelo qual os requisitos do software foram coletados, analisados, documentados e gerenciados ao longo de todo o ciclo de desenvolvimento.

\section{Considerações Finais}

A abordagem adotada para o ensino de Agentes Inteligentes apoia-se na indissociabilidade entre teoria e prática. O Arduino como uma ferramenta pedagógica, mais do que funcionar como um fator motivacional, possibilitou a conversação direta entre diferentes componentes curriculares do ensino, tais como eletrônica, ES e programação, proporcionando assim o trabalho interdisciplinar entre conteúdos de diferentes áreas do saber.

A realização desta atividade buscou proporcionar uma abordagem diferenciada no ensino de IA, de maneira prática, com o incentivo ao trabalho em grupo, autonomia dos estudantes, raciocínio lógico e a resolução de problemas e tomada de decisões. No âmbito acadêmico e institucional, a atividade contribuiu na aplicação de metodologias inovadoras de ensino, especificamente em IA, prática pouco usual nesta área. Com relação à experiência docente, as contribuições envolveram, indubitavelmente, a re-significação das práticas, proporcionando a construção de valores relacionados à educação num sentido de mediação e bidirecionalidade.

\section{Referências}

Alarcão, I. (2013). Professores reflexivos em uma escola reflexiva. Cortez, São Paulo.

Brasil (1996). Lei N 9.394/96. Estabelece as diretrizes e bases da educação nacional. Disponível em <http://www.planalto.gov.br/CCIVIL_03/Leis/L9394.htm>.

Guedes, G. T. A. (2018). UML2: Uma abordagem prática. Novatec, São Paulo.

Libâneo, J. C. (1992). Democratização da escola pública: a pedagogia crítico-social dos conteúdos. Loyola, São Paulo.

Pressman, R. S. (2016). Engenharia de software: uma abordagem profissional. AMGH, Porto Alegre.

Russel S., Norvig P. (2013). Inteligência Artificial. Campus, Rio de Janeiro.

Santos, F. O. (2014). Inteligência Artificial. Elsevier, Rio de Janeiro.

Sommerville, I. (2011). Engenharia de Software. Pearson Prentice Hall, São Paulo. 